\title{
SINERGIA
}

\author{
REVISTA DO INSTITUTO DE CIÊNCIAS ECONÔMICAS, ADMINISTRATIVAS E CONTÁBEIS (ICEAC)
}

\section{APRENDIZAGEM INFORMAL ENTRE TÉCNICOS ADMINISTRATIVOS DE UMA IFE}

\author{
TIELE SILVEIRA CARRASCO \\ FRANCIELLE MOLON DA SILVA*
}

\begin{abstract}
RESUMO
A aprendizagem informal é um processo complexo que envolve indivíduo, ambiente e suas diferentes interações. Na intenção de contribuir com a discussão sobre o tema, tem-se como objetivo compreender os aspectos organizacionais e pessoais que influenciam a aprendizagem informal. Para tanto, realizou-se uma pesquisa exploratória, de abordagem qualitativa, com entrevistas, em profundidade, com técnicos-administrativos em educação (TAEs), lotados em um Instituto Federal de Educação, Ciência e Tecnologia (IF), localizado no Rio Grande do Sul. Os dados obtidos a partir das entrevistas foram analisados por meio de análise de conteúdo. Esta pesquisa identificou que o processo de aprendizagem informal dos TAEs acontece a partir da interação entre os indivíduos, essencialmente por meio de conversas e colaborações com os colegas de trabalho, bem como por pesquisas na internet. Sendo assim, os resultados desta pesquisa indicam que a promoção de ações de integração e socialização entre os servidores técnicos-administrativos, nos institutos federais, pode potencializar a aprendizagem informal.
\end{abstract}

Palavras-chave: aprendizagem organizacional, aprendizagem informal, facilitadores, inibidores, Institutos Federais de Ensino.

\section{ABSTRACT}

Informal learning is a complex process involving individual, environment and their different interactions. In order to contribute to the discussion on the theme, the objective is to understand the organizational and personal aspects that shape informal learning. An exploratory, qualitative approach was carried out from in-depth interviews with administrative technicians in education at a Federal Institute of Education, Science and Technology located in Rio Grande do Sul. This research identified that the process informal learning of TAEs occurs through the interaction between individuals, essentially through conversations and collaborations with co-workers, as well as through Internet searches. Thus, the results of this research indicate that the promotion of integration and socialization actions among administrative technical staff in federal institutes can enhance informal learning.

Keywords: organizational learning, informal learning, facilitators, inhibitors, Federal Institutes of Education.

Recebido em: 20-10-2020 Aceito em: 12-07-2021

\section{INTRODUÇÃO}

Certo dia, Isaac Newton refletia sobre tudo o que aprendeu, mas não compreendia o que mantinha os objetos à superfície dos planetas e a lua na órbita da Terra, tal resposta não estava nos livros que consultara até então; no entanto, ao contemplar uma maçã cair no seu pomar, percebeu que deveria existir um poder de atração entre a Terra e os objetos, eis a Teoria da Gravidade. Assim, o episódio da macieira, conhecido como Fábula da maçã, pode ser descrito como espontâneo, na prática, proveniente da interação do indivíduo com o meio. A descoberta de Newton mudou completamente as concepções sobre objetos terrestres e corpos celestes. Até hoje, uma contribuição desmedida para a física é atribuída à queda de uma maça, ou melhor, a aprendizagem informal de Newton.

Não foi a única. Frederick Taylor, engenheiro mecânico norte-americano, contava seus passos no caminho de casa ao trabalho; em pouco tempo, concluiu que reduzir o esforço e os movimentos inúteis o levava mais rápido ao destino, assim surgiu o estudo dos tempos e movimentos. Um dos maiores princípios da Administração Científica provém da aprendizagem informal de Taylor. Diversas contribuições, em variadas áreas, são produto de uma aprendizagem que não é planejada, conduzida por outrem ou institucionalizada. Nesse sentido, é inegável que a aprendizagem informal mereça destaque.

\footnotetext{
Mestre em Administração pela Universidade Federal do Rio Grande - FURG, pós-graduada em Contabilidade Pública e Responsabilidade Fiscal pelo Centro Universitário Internacional - Uninter, Bacharel em Ciências Contábeis e em Administração (2010), ambos pela Universidade Federal do Rio Grande - FURG. Servidora do Instituto Federal de Ciência e Tecnologia Sul-rio-grandense IFSul no cargo de Contadora. E-mail: tielecarrasco@gmail.com

" Doutora em Recursos Humanos na Universidade Federal do Rio Grande do Sul. Mestre em Administração pela Universidade Federal do Rio Grande do Sul. Professora da Universidade Federal de Pelotas.
} 
A aprendizagem informal (AI) consiste no aprendizado pela prática (ELKJAER, 2004) e tende a ser mais intrínseca ao indivíduo, usualmente, associada a alguma demanda diretamente relacionada ao desempenho no trabalho, ou seja, sua aplicabilidade tem impacto direto no trabalho do indivíduo (COELHO JUNIOR; BORGES-ANDRADE, 2008). Assim, a aprendizagem informal é vista como uma ferramenta sagaz frente à competitividade, uma vez que, com o aumento do escopo e intensidade do trabalho, os indivíduos encontram situações mais complexas e ambíguas, acarretando a intensificação das demandas por conhecimento e habilidades pessoais (CHOI, 2009).

Nesse prisma, a identificação das características pessoais que podem influenciar no desenvolvimento da aprendizagem informal torna-se de fundamental valia à incorporação de novos perfis ao elenco de trabalho, bem como o reconhecimento dos elementos organizacionais, que, aprimorados, possam atuar como facilitadores. Assim, este estudo objetiva compreender os aspectos organizacionais e pessoais que influenciam a aprendizagem informal a fim de que as organizações possam utilizar tais achados para potencializar ou reduzir as barreiras para aprendizagem informal entre as pessoas no ambiente de trabalho.

A discussão sobre aprendizagem informal também se encontra imersa nas discussões do contexto público. Os estudos de Reatto e Godoy (2017) apontam as interações sociais, dos servidores técnicoadministrativos de uma universidade estadual paulista, a partir dos processos e atividades que ocorrem nos contextos de trabalho. Demonstrando, ainda, que as pessoas aprendem durante o trabalho, nas atividades diárias, ao resolver problemas, nas experiências no trabalho, na improvisação, na troca com os colegas.

$\mathrm{Na}$ intenção de complementar as pesquisas nesse campo, elegeu-se o contexto público para a pesquisa empírica, já que o segmento não tem sido privilegiado nas pesquisas desenvolvidas no campo da aprendizagem organizacional no Brasil. E definiram-se os técnicos-administrativos em educação lotados em um instituto federal de ensino do Rio Grande do Sul, como sujeitos da pesquisa, por estarem imersos e mais sujeitos aos impactos das estruturas organizacionais nas suas rotinas de trabalho, bem como pela urgência em pesquisas sobre aprendizagem em setores não lucrativos (REATTO; GODOY, 2017).

Os resultados deste estudo podem contribuir para a reorganização e otimização tanto do design dos ambientes de trabalho para torná-los mais propícios ao aprendizado informal, quanto das políticas de desenvolvimento para que desenvolvam a capacidade dos agentes para resolução de problemas e a habilidade de aprender de maneira independente (LOHMAN, 2005). Uma contribuição teórica do estudo é apontar elementos dos aspectos organizacionais e pessoais que influenciam no processo da aprendizagem informal, considerando o setor público como unidade de análise.

Este estudo está organizado em seções, sendo a introdução já apresentada. Na primeira seção, temse a revisão de literatura sobre a aprendizagem informal; a segunda seção destina-se à apresentação da metodologia; na terceira seção, são apresentados os resultados e, por fim, as considerações finais do estudo.

\section{APRENDIZAGEM INFORMAL}

O processo de aprendizagem humana está relacionado, principalmente, à educação e ao desenvolvimento cognitivo (HILGARD, 1973). Charles Darwin, autor da Teoria Evolucionista, ao colocar em relevo a luta do homem para se adaptar ao ambiente, pela primeira vez, deu foco à aprendizagem como um processo psicológico (HILGARD, 1973).

Nas teorias clássicas da Administração, sob o olhar principalmente de Taylor e Fayol, o elemento básico era a divisão do trabalho (NOGUEIRA; ODELIUS, 2015). Nessa concepção, a aprendizagem estava voltada para o ensino das posições de produção (NOGUEIRA; ODELIUS, 2015). À medida que o modelo mecanicista de Taylor é suplantado, dá espaço a novas abordagens interacionistas que veem o indivíduo não apenas como força de trabalho, mas dotado de inteligência, capaz de construir o conhecimento e interferir no ambiente de trabalho, em um processo de aprendizagem contínua (SOUZA et al., 2013).

Assim, com o pressuposto básico de responder aos anseios de adaptação às mudanças e ao desenvolvimento competitivo das organizações, as concepções de aprendizagem, dentro da Administração, ganharam relevo (ANTONACOPOULOU, 2002). Desse modo, a Aprendizagem Organizacional (AO) busca desvendar como uma organização aprende e os fatores associados a tal processo, por meio de métodos de pesquisa rigorosos (TSANG, 1997).

De acordo com a perspectiva tradicional, a aprendizagem é principalmente relacionada à educação e ao treinamento, na qual há um esforço na transferência de conhecimento de uma fonte conhecedora (um professor, instrutor ou livro) para um receptor que não possui essa informação, ou seja, a Aprendizagem Formal (GHERARDI; NICOLINI; ODELLA, 1998). Dessa forma, o aprender não só é reservado a certos períodos da vida, como também restrito a ocasiões específicas; em suma, separado de qualquer outra atividade na organização.

No entanto, o homem é, na sua essência, um ser social e, assim, impossível de ser entendido fora do contexto da sociedade em que nasce e vive (LA TAILLE, 1992). Desse modo, o aprendizado é uma atividade social contínua, no qual para descobrir o que é para ser feito, quando e como fazê-lo, lança-se à prática 
(GHERARDI; NICOLINI; ODELLA, 1998). "Aprender é fazer uma jornada na terra da descoberta em vez de seguir uma estrada já pavimentada" (BRANDI; ELKJAER, 2011, p. 29).

Assim, esse estudo preconiza a vertente sociocultural (ou social), que pauta a aprendizagem como algo que surge de interações sociais, considerando a aprendizagem como socialmente construída, como um processo político e intrincado na cultura da organização (EASTERBY-SMITH; ARAUJO, 2001). A aprendizagem, nessa concepção, está situada na prática, portanto inclui o aprender fazendo, o aprender trabalhando (ELKJAER, 2001), no qual a socialização e a aprendizagem são processos inseparáveis e constituem-se mutuamente (BRANDI; ELKJAER, 2011). A perspectiva social evidencia a aprendizagem como um processo de interação entre o indivíduo e o contexto (FLACH; ANTONELLO, 2010).

O adjetivo "social" aponta para a localização da aprendizagem, não na mente do indivíduo, mas no sujeito coletivo (GHERARDI, 2001). Entretanto, este estudo ampara-se no julgamento sustentado por Abbad e Borges-Andrade (2004) e Crossan, Lane e White (1999), que, sob uma perspectiva psicológica, consideram a aprendizagem um processo exclusivamente no nível do indivíduo, sendo que seus efeitos podem propagarse pelos grupos ou pela organização no momento em que for institucionalizado.

Quanto ao conteúdo e ao processo, a aprendizagem social enfatiza a informalidade, a improvisação, a ação coletiva, a conversação e a realização dos sentidos; e aprender é de natureza distribuída e provisória (BRANDI; ELKJAER, 2011). Assim, o aprendizado está situado dentro da atividade em curso (LAVE; WENGER, 1991). Portanto, entende-se que a perspectiva social da aprendizagem está intimamente alinhada à aprendizagem informal e, dessa forma, este é o foco deste estudo.

A aprendizagem informal, principalmente no aprendizado de algo novo no trabalho, segundo Lohman (2005), acontece de 8 (oito) maneiras, são as atividades de: conversa com outros, colaboração com outros, observação a outros, compartilhamento de materiais e recursos com outros, pesquisas na Internet, busca em revistas e jornais oficiais, tentativa e erro, e reflexão sobre as próprias ações.

Do mesmo modo, Marsick e Yates (2012), ao analisarem 39 estudos qualitativos sobre aprendizagem informal, constataram que as ações estavam conectadas ao trabalho e às rotinas diárias, cujo estímulo comumente era um desafio, um choque ou uma situação nova. Assim, a aprendizagem acontece em atividades as quais envolvem tentativa e erro, reflexão na ação e sobre a ação, observação de outros, compromisso com o trabalho do outro e solução de problemas com ajuda de terceiros (REATTO; GODOY, 2017).

Os aspectos que influenciam no processo de aprendizagem informal determinam a intensidade e o aproveitamento desse fenômeno. Marsick e Watkins (2001) evidenciam que a aprendizagem informal ocorre sempre que as pessoas têm a necessidade, motivação e oportunidade de aprendizagem. Assim, considerase que a identificação de elementos que configurem a Al pode favorecer, inclusive, aos que pretendem inibila, pois pode auxiliar no mapeamento das variáveis a serem consideradas e controladas.

A aprendizagem informal é, de acordo com Antonacopoulou (2001), influenciada tanto por fatores individuais quanto pela estrutura organizacional. Logo, percebem-se 2 (duas) dimensões a serem exploradas: as características individuais que influenciam a aprendizagem e as estruturas organizacionais.

Alguns estudos buscaram identificar aspectos que impactam na Al. Antonacopoulou (2001) investigou a relação entre os fatores individuais e organizacionais e o impacto da receptividade do indivíduo à aprendizagem utilizando o gerente individual de bancos varejistas como unidade de análise. $O$ estudo mostra que, ao tentar manter o controle do desenvolvimento e aprendizagem dos indivíduos, as organizações limitam a liberdade destes de explorar a variedade de interconexões entre os processos. A autora evidencia a necessidade de mais pesquisas sobre os aspectos individuais para o entendimento da disposição para a aprendizagem.

Lohman (2005) identificou 2 (dois) aspectos que inibem o desenvolvimento das atividades informais de aprendizagem entre professores e profissionais de recursos humanos de escolas públicas americanas: falta de tempo e falta de proximidade com as áreas de trabalho dos colegas. Ainda, assinalou 3 (três) aspectos ambientais que interferem no processo de aprendizagem: uma cultura organizacional não apoiante, falta de vontade para participar das atividades de aprendizagem informal e a inacessibilidade a especialistas dos assuntos de interesse. Este estudo verificou que as características pessoais e dos ambientes de trabalho influenciam a participação em certos tipos de atividades de aprendizagem informal.

Berg e Chyung (2008) verificaram os aspectos que afetam o engajamento na aprendizagem informal (em ordem de classificação): o interesse no campo atual, o acesso ao computador, personalidade, capacidade profissional, relacionamento com colegas, satisfação no trabalho, trabalho em si, ambiente de trabalho, proximidade física e recompensas monetárias.

Já o estudo de Choi (2009) objetivou investigar a influência da aprendizagem formal, características pessoais, e do ambiente de trabalho na aprendizagem informal entre os gestores de nível médio no setor bancário coreano. Os resultados foram: a aprendizagem formal afeta, significativamente, a aprendizagem informal; fatores pessoais afetam, significativamente, a aprendizagem informal; os ambientes de trabalho afetam, diretamente, a aprendizagem informal, e as características pessoais e do ambiente de trabalho afetam a aprendizagem formal. 
Caldeira e Godoy (2011), tendo como objeto de estudo a Petrobrás, verificaram quais aspectos foram percebidos pelos gestores como favoráveis ou como obstáculos à aprendizagem. Assim, concluíram que a aprendizagem é dificultada pela ineficiência dos processos de comunicação e facilitada pelos processos de avaliação de desempenho.

Costa (2011), ao investigar os aspectos facilitadores e inibidores da aprendizagem organizacional em indivíduos que participaram do programa trainee da General Eletric do Brasil, identificou entre os fatores que contribuem para a aprendizagem: a cultura de aprendizagem, o engajamento do indivíduo no processo, a oferta de recursos e a destruição de barreiras de comunicação entre as pessoas; já entre os inibidores: as rotinas organizacionais defensivas, a visão restrita à empresa, os bloqueios na comunicação interpessoal, a pressão por resultados e o desinteresse de iniciativa pessoal.

Nilsson e Rubenson (2014) propuseram explorar os determinantes da aprendizagem formal e informal entre maiores de 18 anos empregados no Canadá. As análises de regressão indicaram que a idade é inversamente associada à aprendizagem informal, de modo que a participação diminuiu com a idade. O nível de escolaridade foi, significativamente, associado às ações de aprendizagem formal, quanto maior escolaridade, maior interesse em treinamentos e capacitação. Um grau moderado de intensidade de trabalho foi associado a uma maior probabilidade de se combinar educação e aprendizagem informal.

Wahab, Saad e Selamat (2014), ao investigar os inibidores do ambiente de trabalho ao ambiente de aprendizagem informal entre contadores na Malásia, constataram falta de tempo devido à carga de trabalho pesada, falta de recompensas significativas, falta de fundos, influência limitada sobre o funcionamento da empresa e falta de apoio de outros como inibidores para as atividades de aprendizagem.

Reatto e Godoy (2017), com o objetivo geral de compreender como ocorrem as experiências de aprendizagem vivenciadas pelos técnico-administrativos de uma faculdade em seus locais de trabalho, verificaram que a distância geográfica entre as unidades, a falta de clareza na comunicação e a superioridade no tratamento de docentes em relação ao técnico-administrativo foram destacados pelos entrevistados como aspectos influenciadores do clima e da aprendizagem organizacionais.

Dentre esses estudos, a proposta de segregação entre aspectos pessoais e organizacionais é claramente adotada apenas em Antonacopoulou (2001), por meio de uma pesquisa qualitativa, sem parametrização. Entre os estudos empíricos realizados no cenário brasileiro, dentro da temática de fatores facilitadores e inibidores da aprendizagem organizacional, identificou-se Caldeira e Godoy (2011) e Costa (2011), ambos com abordagem qualitativa.

Elkjaer (2001) aponta que a base da diferença de resultados está principalmente relacionada ao fato de que cada pessoa reage a uma situação de acordo com a sua experiência individual. Para entender as características pessoais que balizam a aprendizagem informal, é importante considerar que algumas podem favorecer a aprendizagem, já outras podem inibi-la.

A personalidade é uma forma de identificar e rotular certas características humanas. Apoiando-se, especialmente, em Antonacopoulou (2001), concebe-se a personalidade como um aspecto com melhores possibilidades de explicar o engajamento em atividades de aprendizado informal. Optou-se por adotar os Cinco Grandes Fatores (CGF) que resumem um conjunto complexo de diferenças individuais em cinco traços básicos universais da personalidade humana (ROBBINS, 2002), descritas no Quadro 01.

\begin{tabular}{|l|l|}
\hline \multicolumn{1}{|c|}{ Quadro 1 - Aspectos Pessoais } \\
\hline Fator & \multicolumn{1}{c|}{ Descrição } \\
\hline Extroversão & $\begin{array}{l}\text { Relacionada às formas como as pessoas interagem com os demais (NUNES; HUTZ, } \\
\text { 2006), representa o quão a pessoa é comunicativa, falante, ativa, assertiva, } \\
\text { responsiva e gregária e o quanto tem facilidade para estabelecer interações sociais } \\
\text { dinâmicas (PASSOS; LAROS, 2015; NUNES; HUTZ, 2006). }\end{array}$ \\
\hline Socialização & $\begin{array}{l}\text { Descreve a qualidade das relações interpessoais dos indivíduos (NUNES; HUTZ, } \\
\text { 2007), uma tendência a demonstrar empatia, altruísmo e comportamentos pró-social, } \\
\text { revela em que medida a pessoa tem capacidade para estabelecer relações com } \\
\text { qualidade, de forma harmoniosa, agradável, empática (PASSOS; LAROS, 2015). }\end{array}$ \\
\hline Consciência & $\begin{array}{l}\text { Configura-se como o elemento que afere o quanto a pessoa é focada, realizadora, } \\
\text { apresenta autocontrole e tem disposição para buscar seus objetivos (PASSOS; } \\
\text { LAROS, 2015). }\end{array}$ \\
\hline Neuroticismo & $\begin{array}{l}\text { Consiste na forma como uma pessoa vivencia as experiências negativas, indicando o } \\
\text { seu grau de estabilidade emocional (PASSOS; LAROS, 2015). As pessoas com } \\
\text { estabilidade emocional costumam ser calmas, autoconfiantes e seguras (ROBBINS, } \\
\text { 2002). }\end{array}$ \\
\hline $\begin{array}{l}\text { Abertura para } \\
\text { experiências }\end{array}$ & $\begin{array}{l}\text { Identifica alguém em termos de seus interesses e seu fascínio por novidades, sua } \\
\text { imaginação, pendores artísticos, sensibilidade e intelectualidade (ROBBINS, 2002). }\end{array}$ \\
\hline
\end{tabular}


Segundo Robbins (2002), a consciência é previsor de desempenho de todos os grupos ocupacionais. Logo, indivíduos confiáveis, cuidadosos, organizados e persistentes tendem a apresentar um desempenho superior no trabalho na maioria das ocupações. As evidências também apontaram a Extroversão como a dimensão da personalidade que pode prever o desempenho em posições gerenciais e de vendas, já que essas ocupações envolvem muita interação social (ROBBINS, 2002).

Além dos aspectos pessoais, deve-se considerar os aspectos organizacionais que influenciam a aprendizagem informal. A estrutura organizacional e as relações sociais, dentro do ambiente de trabalho, são definidas pela estrutura social, pelo sistema de relações de obrigação e poder e pelas condições de legitimidade (LAVE; WENGER, 1991; GHERARDI; NICOLINI; ODELLA, 1998; BRANDI; ELKJAER, 2011). Por isso, a aprendizagem também está sujeita ao controle social e aos interesses sociais (GHERARDI, 2001).

O espaço organizacional constitui-se de bens materiais, esquemas físicos, linguagens, documentos, regramentos, ordens, limites. Esse arranjo influencia no modo como as interações pessoais ocorrem, portanto é um elemento decisivo para a aprendizagem (REATTO; GODOY, 2017). Assim, as características do ambiente de trabalho definem a percepção das condições como suscetíveis de promover ou inibir a participação ou engajamento em atividades de aprendizagem no trabalho (CHOI, 2009).

É notório que as características organizacionais que podem influenciar a aprendizagem informal são, em primeira instância, indetermináveis. Desse modo, buscou-se um conjunto de variáveis que pudessem conduzir a pesquisa, em certo ponto, por um caminho predeterminado. Assim, priorizou-se um elenco que apresentasse similaridade de ambiente e contexto social e, mais importante, passíveis de apropriação para classificação de elementos que configurem a aprendizagem informal.

Sendo assim, optou-se por considerar um grupo de variáveis identificado por Lima (2013), que analisou competências coletivas no serviço público brasileiro e identificou 8 (oito) fatores determinantes. Sucumbindo as proposições teóricas a respeito das características e das disposições individuais (já consideradas nos aspectos pessoais) e o Plano de Carreira e Política Nacional de Desenvolvimento de Pessoal (PNDP) (específico às competências), utilizar-se-ão os demais 6 (seis) aspectos, conforme apresentado no Quadro 02.

\begin{tabular}{|c|c|}
\hline Fator & Descrição \\
\hline Papel do gestor & $\begin{array}{l}\text { O gestor tem papel de patrocinador da aprendizagem (CONLON, 2004), logo sua } \\
\text { postura, frente à aprendizagem, é fundamental (COSTA, 2011). Os gerentes } \\
\text { considerados matofóbicos caracterizam-se como conservadores, apáticos e com } \\
\text { pouca iniciativa pessoal, são, ainda que cientes da necessidade de aprender, } \\
\text { resistentes ao aprendizado. Já os gerentes filomáticos são propensos à } \\
\text { aprendizagem, portanto mais enérgicos e ativos na criação de oportunidades, } \\
\text { procurando aperfeiçoamento e explorando os processos de aprendizagem } \\
\text { (ANTONACOPOULOU, 2001). }\end{array}$ \\
\hline Comunicação & $\begin{array}{l}\text { Quando o processo de comunicação não sofre bloqueios ou desvios, há uma } \\
\text { predisposição para que o desempenho e interações das pessoas sejam de maneira } \\
\text { satisfatória; ao passo que falhas e controle excessivo por parte da organização do que } \\
\text { é comunicado tendem a prejudicar o desenvolvimento do processo de aprendizagem } \\
\text { informal (COSTA, 2011; ANTONACOPOULOU, 2001). }\end{array}$ \\
\hline $\begin{array}{l}\text { Dinâmica das } \\
\text { atividades }\end{array}$ & $\begin{array}{l}\text { Refere-se à execução das tarefas e configuração da rotina diária de trabalho, à busca por } \\
\text { novas ideias, à limitação de tempo para dedicação à atividade de aprendizagem (WAHAB; } \\
\text { SAAD; SELAMAT, 2014). Um clima organizacional construtivo encoraja os indivíduos a } \\
\text { ter atitudes positivas e reconhecer a necessidade de desenvolver a aprendizagem } \\
\text { (ANTONACOPOULOU, 2001). Por outro lado, a aprendizagem informal pode ser } \\
\text { dificultada por estruturas organizacionais restritivas (NILSSON; RUBENSON, 2014). }\end{array}$ \\
\hline Estrutura Física & $\begin{array}{l}\text { A disposição física em uma organização estimula a aproximação de alguns indivíduos } \\
\text { e afasta outros (SCHERMERHORN JR.; HUNT; OSBORN, 1999). Assim, a estrutura } \\
\text { física pode determinar a proximidade e o acesso à informação (CONLON, 2004). }\end{array}$ \\
\hline $\begin{array}{l}\text { Integração da } \\
\text { equipe }\end{array}$ & $\begin{array}{l}\text { A maneira como as pessoas percebem o mundo é mais resultado do processo de } \\
\text { interação e construção coletiva do que de sua individualidade (COELHO JUNIOR; } \\
\text { MOURÃO, 2011). Portanto, a configuração e consistência de uma equipe de trabalho } \\
\text { pode determinar a aprendizagem, já que os grupos tendem a se ajustar entre seus } \\
\text { membros. }\end{array}$ \\
\hline $\begin{array}{l}\text { Quadro de } \\
\text { pessoal: }\end{array}$ & $\begin{array}{l}\text { Abarca o quantitativo de pessoal, a configuração dos setores e a qualificação dos } \\
\text { indivíduos. Ainda, pode ser uma das razões que desencadeia a desmotivação para a } \\
\text { aprendizagem, uma vez que aquele que sabe mais, provavelmente, será cobrado a } \\
\text { fazer mais (LIMA, 2013). }\end{array}$ \\
\hline
\end{tabular}

Fonte: Lima, 2013. 
Isto posto, observa-se que os fatores organizacionais parecem bastante interligados e atuam ora como facilitadores, ora como limitadores, de acordo com a estrutura organizacional (ANTONACOPOULOU, 2001). Na seção seguinte, são apresentados os aspectos metodológicos adotados no estudo.

\section{METODOLOGIA}

Para que o objetivo de compreender os aspectos organizacionais e pessoais que influenciam a aprendizagem informal seja alcançado, este estudo pauta-se no processo lógico dedutivo pelo qual se pode tirar de uma ou várias proposições uma conclusão que delas decorrem por força puramente lógica. Conforme Malhotra (2006), esta pesquisa pode ser classificada como, primeiramente, uma pesquisa exploratória, a qual visou prover critérios e compreensão do problema em questão e, posteriormente, uma pesquisa descritiva, que tem como concepção básica descrever características por meio de levantamentos.

A partir da compreensão do tema, identificaram-se, na literatura, caminhos teóricos a serem explorados na pesquisa de campo. A etapa descritiva consiste em uma abordagem qualitativa, que tem como objetivo alcançar uma compreensão qualitativa das razões e motivações subjacentes no contexto do problema (MALHOTRA, 2006).

Nesse estudo, elegeram-se os técnicos-administrativos em educação (TAEs) lotados em um Instituto Federal de Educação, Ciência e Tecnologia (IF), localizado no Rio Grande do Sul. A escolha justifica-se pelo papel social das organizações públicas que merecem o olhar dos pesquisadores para apoio no aprimoramento às constantes e aceleradas mutações devido ao impacto de novas tecnologias e da escassez de recursos humanos e financeiros (REATTO; GODOY, 2017). Excluem-se os docentes que, por se relacionarem estreitamente com os alunos, agentes de fora do contexto de trabalho, entende-se que o processo de aprendizagem informal acontece de maneira diferenciada ao dos técnicos administrativos. Ademais, por entender que o trabalho dos TAEs está mais diretamente associado aos processos organizacionais.

A coleta de dados deu-se por meio de entrevistas em profundidade. A entrevista piloto foi realizada anteriormente às demais, com o objetivo de verificar inadequações no roteiro de entrevistas. Uma vez não identificados problemas no roteiro, as demais foram realizadas. Desse modo, selecionou-se, por conveniência, os servidores com disponibilidade e facilidade de acesso pela entrevistadora, resultando em um total de 07 (sete) entrevistas.

As entrevistas em profundidade seguiram um roteiro semiestruturado, baseado em Lima (2013). O roteiro garante a discussão de questões indispensáveis, mas que permitem, também, espaço para discussão aberta relacionada ao tema. As entrevistas foram gravadas, conforme recomendação de Triviños (2009), e, posteriormente, transcritas.

Os dados obtidos a partir das entrevistas foram analisados conforme as etapas do processo de análise de conteúdo de Triviños (2009). Primeiramente, a pré-análise, que consiste na organização do material, neste caso, abrange a escuta e degravação das entrevistas, com a anotação das características do participante, tempo de entrevista e data. A segunda etapa versa na descrição analítica, ou seja, a categorização e classificação do material obtido de acordo com a teoria referenciada, conforme os quadros 01 e 02 . Por fim, a interpretação referencial, que compreende a reflexão, a intuição e o estabelecimento de relações. Assim, 0 processo de análise dos dados qualitativos consistiu na identificação de elementos temáticos e separação desses, apresentação dos dados e formulação de conclusões.

A seção seguinte é dedicada à apresentação dos resultados da pesquisa.

\section{RESULTADOS}

A pesquisa qualitativa buscou o alcance do objetivo geral do estudo. Sendo assim, as entrevistas foram realizadas no ambiente de trabalho dos TAEs durante o mês de outubro de 2017 e tiveram duração média de 25 minutos. A tabela 01 apresenta a descrição dos entrevistados.

Tabela 1 - Descrição dos entrevistados

\begin{tabular}{c|c|c|c|c}
\hline Entrevistado & Sexo & Idade & Ingresso & Cargo de Chefia \\
\hline 1 & Feminino & 49 & 2004 & Não \\
\hline 2 & Feminino & 40 & 2013 & Sim \\
\hline 3 & Masculino & 54 & 1993 & Não \\
\hline 4 & Masculino & 38 & 2007 & Não \\
\hline 5 & Feminino & 33 & 2012 & Não \\
\hline 6 & Masculino & 36 & 2013 & Sim \\
\hline $7^{*}$ & Feminino & 30 & 2011 & Sim \\
\hline
\end{tabular}

Fonte: Dados da pesquisa (2017) 
Primeiramente, são apresentados os resultados que indicam como ocorre o processo de aprendizagem informal na instituição. Posteriormente, os elementos identificados são apresentados nas categorias aspectos pessoais e organizacionais.

\subsection{O processo de aprendizagem informal}

A partir das entrevistas, identificou-se que o processo de aprendizagem se dá por meio de conversa com os colegas, pesquisa em legislação, consulta a sites de busca e tentativa e erro, tal qual constatado por Lima (2013) e sugerido por Lohman (2005), Coelho Junior e Mourão (2011) e Reatto e Godoy (2017).

Nesse sentido, o processo de aprendizagem ocorre, predominantemente, a partir do contato interpessoal, como expresso por 5 dos 7 entrevistados. Segue um dos relatos:

Através da conversa, principalmente do relacionamento (...), conversa no dia a dia. Claro, tem leitura e tudo, mas eu acho que com o dia a dia as experiências é através de conversa mesmo, relacionamento interpessoal (Entrevistado 6).

Outra possibilidade retratada nas entrevistas está no uso da tecnologia, da internet, na busca por aprendizado, tal qual salientado por Berg e Chyung (2008). Já o entrevistado 4 evidencia o trabalho rotineiro, repetitivo e previsível, considerado característico do setor público, de modo que não identifica novas atividades e a necessidade de aprendizado na sua rotina de trabalho. Esse fato sugere uma dificuldade na identificação da aprendizagem, por tratar-se de algo que, por vezes, dá-se de maneira natural e não consciente (NOGUEIRA; ODELIUS, 2015; ANTONELLO, 2011; EASTERBY-SMITH; ARAUJO, 2001).

Sendo assim, pode-se inferir que o processo de aprendizagem informal é identificado, predominantemente, como aquele que emerge pela interação social (GHERARDI; NICOLINI; ODELLA, 1998), como indica a vertente social da aprendizagem. Nesse sentido, as trocas, os compartilhamentos a partir da conversa e das interações entre as pessoas foram identificados. Resultados que vão ao encontro da pesquisa de Reatto e Godoy (2017), uma vez que os participantes desse estudo apontaram que, para eles, o processo de aprendizagem ocorre tanto no processo de trabalho quanto na realização das atividades.

Para os entrevistados, conversar, trocar ideias, resolver problemas, ensinar o colega e colaborar com o trabalho dos outros são pontos que contribuem com o aprendizado dos todos. Essa constatação vem a partir do argumento de que muitas das construções dos indivíduos são possíveis a partir da interação e das trocas entre as pessoas. Sendo que o contato com os colegas acaba sendo um dos principais apontamentos, sustentando, também, os resultados encontrados em Reatto e Godoy (2017).

\subsection{Aspectos Pessoais}

Antonacopoulou (2001) afirma que as múltiplas realidades dos indivíduos os induzem a perceber diferentes aspectos e interpretar as mesmas questões de diferentes formas, tal qual observado nas respostas dos entrevistados. Questionados sobre seu sentimento em relação a uma nova tarefa, foram relatados sentimentos de desafio, raiva e desânimo, ansiedade, surpresa, medo, satisfação e curiosidade. Destaca-se a ansiedade nos relatos sobre os aspectos que dificultariam a execução da atividade, como relata 0 entrevistado 03, ao afirmar ter ansiedade e, por esse motivo, tenta imaginar como resolver determinadas tarefas sem ajuda de outrem.

Além da ansiedade, outro sentimento frisado, nas entrevistas, é o medo que pode exprimir a presença de uma repressão velada e não verbal no ambiente de trabalho, o que, dessa forma, pode indicar uma característica de centralização do poder ou menor flexibilidade, portanto uma barreira para a interação dos indivíduos e para a construção de um clima organizacional construtivo (NILSSON; RUBENSON, 2014).

$\mathrm{O}$ questionamento referente às características pessoais que poderiam ajudar no desenvolvimento de uma nova tarefa retornou hesitação e respostas diversas. Tal resultado reforça a proposição de Coelho Junior e Borges-Andrade (2008) de que, sem classificação ou balizamento, dada a infinidade de possibilidades de resposta, uma convergência e comparação aos resultados de outros estudos é dificultada. Sendo assim, buscando uma sistematização, foram apresentados, em um segundo momento, os cinco traços de personalidade. Por um lado, a apresentação do modelo CGF facilitou o diálogo, por outro, como esperado, enrijeceu e limitou as possibilidades de resposta.

A consciência foi o fator mais evidente nos relatos, que pode indicar a percepção por parte do indivíduo de uma relação direta entre aprendizado e treinamento, o que, de certa forma, exige pessoas mais focadas. Tal evidência está de acordo com o verificado por Robbins (2002), de que a Consciência é um previsor de desempenho no trabalho. Segundo o entrevistado 05, o fator que mais dificulta a aprendizagem informal é a Consciência, já que acredita que lhe faltam organização e disciplina.

Já o Neuroticismo aparece como um aspecto negativo para a convivência no ambiente de trabalho. $O$ 
descontrole emocional é um fator apontado pelo Entrevistado 03.

A análise das entrevistas demonstrou que o sentimento de ansiedade é recorrente e permeia a vida de alguns. Dessa forma, pode-se sugerir que o Neuroticismo não se mostra significante, pois se trata de uma constante na vida do indivíduo, não sendo potencialmente capaz de influenciar ou determinar a aprendizagem informal.

A Abertura para experiências foi indicada, para os indivíduos receptivos a mudanças, como um impulsionador, a despeito dos que se sentem menos à vontade em ambientes dinâmicos, que indicam como aspecto negativo, em conformidade com Caldeira e Godoy (2011). De acordo com o Entrevistado 04, a Abertura para experiências é o traço que mais o atrapalha por considerar-se muito cético.

Os traços Extroversão e Socialização sofreram da problemática de associação e sinonímia entre os termos, o que sugere a existência de uma noção de proporcionalidade entre os traços, ou seja, quanto mais extrovertido, mais sociável é o indivíduo. Além disso, são considerados traços que facilitam a aprendizagem por proporcionar um maior relacionamento interpessoal. A fim de elucidar essa associação entre a extroversão e a socialização, traz-se o relato do entrevistado 03:

A primeira, porque eu sou, eu me acho bastante extrovertido. Até vem um pouco de socialização, eu acho que as duas, principalmente. Porque eu me considero um ser bem sociável, nunca tive dificuldade de me comunicar com as pessoas (Entrevistado 3).

Os fatores Abertura para Experiências, Extroversão e Socialização foram evidenciados como preditores da aprendizagem informal, principalmente, pelos indivíduos que priorizam as conversas e interações sociais no aprendizado. Dessa forma, entende-se que os indivíduos que possuem altos escores em Extroversão, Socialização e Abertura para Experiências estão mais propensos à aprendizagem social, o que corrobora com os estudos de Robins (2002); Nunes e Hutz (2006); Nunes e Hutz (2007); Passos e Laros (2015) e implica afirmar que os aspectos pessoais influenciam a aprendizagem individual.

\subsection{Aspectos Organizacionais}

Já as questões relacionadas aos aspectos organizacionais que são potenciais para o desenvolvimento da aprendizagem informal (ANTONACOPOULOU, 2001), a percepção quanto ao apoio institucional para a aprendizagem por parte dos entrevistados, em primeiro momento, é a de desamparo. O Entrevistado 1, afirma que não percebe a instituição ajudando, que se sente apoiado nas pessoas e nas ferramentas disponíveis no sistema de trabalho.

Assim, pode-se verificar pelos relatos que os entrevistados não evidenciam políticas positivas ou procedimentos que incentivem a aprendizagem informal na instituição, como ressaltado por Choi (2009).

O entrevistado 2 evidencia o papel institucional pela proposição de desafios aos servidores. A afirmação vai ao encontro das experiências de aprendizagem informal verificadas por Reatto e Godoy (2017) e Marsick e Yates (2012), que evidenciam a aprendizagem integrada ao trabalho e às rotinas diárias, cujo gatilho geralmente é um choque, um desafio ou uma situação de surpresa. O Entrevistado 02 menciona que a organização influencia no seu aprendizado quando delega atividades que não têm conhecimento prévio, o obrigando a aprender.

Por outro lado, o trabalho rotineiro é identificado igualmente como uma limitação à aprendizagem, como ressalta o entrevistado 4, ao mencionar que a tendência é a de que os servidores fiquem executando sempre a mesma atividade dentro de um mesmo contexto de trabalho. Assim, pode-se vislumbrar diferentes percepcões a respeito do trabalho, ora evidenciada como desafiador, ora como repetitivo.

$\mathrm{O}$ apoio institucional também é identificado por meio dos colegas. Nesse sentido, a referência do entrevistado 3 evidencia o chamado suporte psicossocial à aprendizagem (COELHO JUNIOR; MOURÃO, 2011).

Se formos para o lado que nós, todos servidores, somos instituição, eu já atribuo aos meus colegas mesmo (Entrevistado 3).

E a influência das estruturas organizacionais no aprendizado é reconhecida pelos entrevistados pelas suas ações e posicionamentos em relação, essencialmente, à aprendizagem formal. O Entrevistado 01 afirma que a instituição ajudaria, na aprendizagem, dando treinamento a partir da análise das necessidades de cada servidor ou pela avaliação dessa necessidade de treinamento pela chefia ou pelos próprios colegas.

Esses relatos vão ao encontro de Flach e Antonello (2010) que indicam Al como de difícil percepção, avaliação e verificação. Dessa forma, o entendimento do apoio institucional para a aprendizagem está, para alguns dos entrevistados, estritamente relacionada às ações de aprendizagem formal, ainda que afirmem resolver suas questões e dúvidas de trabalho essencialmente por meio de conversa com os seus pares de trabalho, como observado por Costa (2011). É o que ocorre com o Entrevistado 01, que afirma que a 
instituição ajuda oferecendo treinamento, mas resolve seus problemas "conversando, perguntando e contando das dificuldades daqui e dali de desenvolver determinada tarefa" (Entrevistado 1).

Diante disso, foram apresentados os 6 (seis) aspectos organizacionais. Em geral, os entrevistados acabaram por pontuar os elementos organizacionais em relação ao seu trabalho como um todo e a influência de cada um no seu dia a dia. Esse resultado segue a premissa anteriormente revelada, de que os participantes têm dificuldade em relacionar o aprendizado às estruturas organizacionais, por mais que fosse salientada a ligação.

Com relação ao papel do gestor, foi evidenciada a importância do gestor como apoiador e incentivador, como encontrado por Caldeira e Godoy (2011).

Se tu estás em um lugar de chefia ou de coordenação ou de direção ou, não sei, que tu tens o poder, e tu precisa que essas pessoas que estão subalternas a ti façam determinadas coisas tu tens que dar apoio para elas, para elas te darem o retorno que tu queres, e às vezes não é bem assim (Entrevistado 1).

Quanto ao perfil do gestor, pode-se perceber uma aproximação ao conceito de matofobia, entretanto, melhor descrito como conservador, cauteloso, do que propriamente uma aversão a novas formas de desempenhar o trabalho ou a aprendizagem. Nesse sentido, a partir das entrevistas, pode-se perceber que 0 poder e o controle apresentam-se como fatores organizacionais, nesse caso, na figura do gestor. Esse resultado está em consonância ao desvendado por Antonacopoulou (2001) e Lima (2013).

O papel da comunicação tanto em promover quanto inibir a aprendizagem e a importância da comunicação dentro da instituição é observada, como pode-se verificar por meio da fala do entrevistado 7 .

Acho que a parte positiva da comunicação, se ela é bem-feita, é que tu consegues sanar dúvidas (...), tu consegues tirar, por exemplo, um aprendizado. Se tu tens uma comunicação desenvolvida tu consegues meios para fazer um trabalho melhor, tipo tu podes não saber fazer, mas tu conheces a pessoa que sabe, vai lá e tenta aprender (...). Mas também acho que ela pode ser o que é mais negativo, porque através da comunicação tu passas várias informações, que podem ser falácias, tu podes inclusive ensinar uma coisa errada, pode criar um clima organizacional muito ruim que tu não consigas ter prazer em trabalhar, (...) então eu acho que a comunicação é o ponto bom e ruim (Entrevistado 7).

Lima (2013) identificou o que chamou de "arquivamento individual do conhecimento", ou seja, a retenção do conhecimento ou do que foi aprendido. Tal evidência pôde ser verificada no relato do entrevistado 06, ao afirmar que o problema da realização de um curso é que, muitas vezes, o conhecimento fica apenas com a pessoa que participou, não sendo compartilhado com outras pessoas e, ainda, muitas vezes, aquele conhecimento não é nem utilizado na prática do trabalho.

A posse de informações como poder de barganha foi mencionada, tal qual identificado por Lima (2013) e Costa (2011). Conlon (2004) também salienta o receio de compartilhamento de informações para manutenção da individualização do cargo como limitador da aprendizagem informal.

Bom, eu creio que as pessoas têm egos, fortes e que atrapalham bastante o aprendizado no sentido de apropriação da informação sabe, eu acho que existe muita apropriação de informação como poder de barganha (Entrevistado 7).

No que tange a Dinâmicas das atividades, que se refere ao tempo, à organização e à valorização de novas formas de executar o trabalho, verificou-se que o tempo é considerado, em geral, escasso. Lohman (2005) e Wahab, Saad e Selamat (2014) já indicavam que a intensificação do trabalho restringe a participação dos indivíduos nas atividades de aprendizagem.

Eu acho que ter mais tempo, mais tempo para esse tipo de conversa, de repente parar, por que a gente vive em um trabalho rotineiro, e aí tu ficas focado na rotina e muitas vezes tu não paras para pensar o que tem que fazer, para te planejar, para tentar melhorar o teu relacionamento, o teu trabalho (Entrevistado 6).

Desse modo, sugere-se que o tempo atua como um limitador, mas não como um determinante, pois a aprendizagem desenvolve-se apesar da restrição de tempo.

Ao contrário do identificado por Lima (2013), o espaço físico foi mencionado como um ponto positivo na instituição, portanto atuando como um facilitador da aprendizagem informal por possibilitar encontros entre os colegas. De acordo com o Entrevistado 01, a estrutura física é boa e permite o acesso a todos os colegas contando, inclusive, com várias áreas de convivência que permitem o encontro entre as pessoas.

Os relatos enfatizam a posição do espaço físico como facilitador, como citado por Lohman (2005), de 
encontro aos demais aspectos, considerados inibidores. No entanto, o espaço físico, ainda que possibilite, não determina a aproximação dos indivíduos, uma vez que outras formas de contato com os colegas são utilizadas, como telefone e internet.

No tocante à integração da equipe, verificou-se uma dada importância, por parte dos entrevistados, aos seus colegas de trabalho. Conforme a teoria social da aprendizagem, a integração da equipe determina a aprendizagem (BRANDI; ELKJAER, 2011). O depoimento a seguir demonstra a relação entre ambiente e equipe de trabalho. $O$ Entrevistado 03 afirma que, para atender às demandas, um bom ambiente de trabalho deve contar com equipes, a despeito do trabalho individual que se torna mais complicado.

Com relação ao Quadro de Pessoal, a limitação de pessoal é mencionada em todas as entrevistas. Assim, pode-se inferir que instituições que distribuem melhor seu quadro de pessoal e fornecem materiais e recursos em boas condições influenciam positivamente a aprendizagem informal. Nos discursos a respeito da Dinâmica das atividades e do Quadro de Pessoal, é dada ênfase à sobrecarga de trabalho, à falta de tempo, ao excesso de tarefas e ao quadro de pessoal limitado.

Por fim, no que se refere ao processo de aprendizagem informal, pode-se inferir que as conversas interpessoais e buscas na internet são as mais evidenciadas, tanto na análise descritiva das questões quanto nos relatos dos entrevistados. E, de posse de todos os resultados, é possível perceber que os aspectos pessoais e os organizacionais podem ser preditores e inibidores do processo de aprendizagem dos indivíduos entrevistados e que a organização do trabalho é vista como propícia ao desenvolvimento da aprendizagem informal, sendo que as interações são naturais e presentes e são condicionantes à aprendizagem também.

\section{CONSIDERAÇÕES FINAIS}

O objetivo deste estudo foi compreender os aspectos organizacionais e pessoais que influenciam a aprendizagem informal dos técnicos administrativos em educação em um instituto federal situado no Rio Grande do Sul. Para que o objetivo deste estudo fosse alcançado, realizou-se uma pesquisa descritiva, exploratória, de abordagem qualitativa, com entrevistas em profundidade com análise dos dados realizada por meio de análise de conteúdo.

A aprendizagem informal foi versada à luz da teoria social da aprendizagem que determina a aprendizagem como uma construção social que emerge nos processos coletivos e na prática do trabalho. Esta pesquisa identificou que o processo de aprendizagem informal dos TAEs acontece a partir da interação entre os indivíduos, essencialmente, por meio de conversas e colaborações com os colegas de trabalho, bem como por pesquisas na internet, em consonância com os conceitos norteadores utilizados neste estudo.

A confluência entre a disposição individual e as condições organizacionais promovem o desenvolvimento da aprendizagem informal. Assim, a partir dos resultados obtidos neste estudo, pode-se verificar que a premissa de que as organizações mais flexíveis tendem a promover a aprendizagem informal com mais facilidade, ao passo que organizações com estruturas rígidas tendem a inibir esse processo. De fato, os fatores que facilitam a aprendizagem estão relacionados a aspectos que atribuem plasticidade às organizações, como a qualidade do relacionamento entre as equipes, um bom espaço físico, comunicação fluída e um gestor apoiador. No tocante aos aspectos pessoais, observa-se um quadro semelhante, pessoas mais propensas às ações de aprendizagem informal são aquelas consideradas flexíveis, ou ainda, mais abertas a novas situações. Nesse sentido, observa-se que a Extroversão, a Socialização e a Abertura para Experiências mostram-se aspectos de maior relevância. Sendo assim, pode-se constatar que tanto os aspectos pessoais quanto os organizacionais facilitadores relacionam-se com a flexibilidade e com a abertura para aprendizagem, já os aspectos inibidores estão relacionados a barreiras a essa elasticidade.

A partir dos resultados, pode-se inferir que instituições que buscam potencializar a aprendizagem informal devem, primeiramente, considerar as características pessoais dos servidores, atentando para a formação de equipes com indivíduos com personalidade extrovertida, sociável e aberta a experiências; bem como forneçam meios para que as equipes se comuniquem sem barreiras, disponham de espaço físico adequado, incentivem a formação e integração das equipes, distribuam o tempo e as tarefas adequadamente, incitem a valorização de novas formas de organizar o trabalho, desenvolvam gestores mais participativos e incentivadores. Em outras palavras, este estudo fornece parâmetros e indicadores para que as organizações possam verificar e otimizar seus processos a fim de que promovam a aprendizagem informal.

Sendo assim, os resultados desta pesquisa indicam que a promoção de ações de integração e socialização entre os servidores técnicos-administrativos, nos institutos federais, pode potencializar a aprendizagem informal. A socialização e a integração no setor público mostram-se uma alternativa viável e concreta, tanto para retificar e aprimorar equipes de trabalho quanto para desenvolver e refinar certos traços individuais de personalidade, como Socialização, Extroversão e Abertura para Experiências. As ações de socialização e integração, além da melhoria da ambientação e satisfação dos servidores, podem ser gerenciadas estrategicamente a fim de maximizar o desempenho dos indivíduos no trabalho.

Em tempo, ressalta-se que os resultados desta pesquisa convergem para o sustentado na pesquisa de 
Brandi e Elkjaer (2011), que determina que o conhecimento é resultado da participação do indivíduo nas práticas e rotinas organizacionais e de uma complexa rede de relacionamentos, e Marsick e Watkins (2001), que verificam que a Al é motivada, direcionada e sustentada pelos interesses e intenções próprias dos indivíduos (MARSICK; WATKINS, 2001).

Alguns aspectos destacaram-se na pesquisa, como o tempo e a ansiedade, elementos considerados agentes no desenvolvimento da aprendizagem informal, mas não determinantes, já que a escassez de tempo e o sentimento de ansiedade mostram-se permanentes no dia a dia de trabalho. Além disso, a hesitação em relação às características pessoais evidencia uma tendência humana em observar melhor o ambiente do que a si próprio, especialmente no tocante a características socialmente consideradas negativas. Também, observou-se uma dificuldade em relação à percepção do papel organizacional além da promoção da aprendizagem formal.

Como limitações do estudo, pode-se elencar a ausência de parâmetros sobre aspectos pessoais e organizacionais relacionados à aprendizagem informal, fato que compeliu a pesquisa a determinar fatores que carecem de sustentação teórica maior. Em contrapartida, este estudo expande possibilidades dentro da metodologia da pesquisa qualitativa ao utilizar categorizações que podem ajudar a sistematizar os achados sobre a aprendizagem informal como indicam Coelho Junior e Borges-Andrade (2008).

Como sugestões para pesquisas futuras, aponta-se a investigação de outros elementos pessoais e organizacionais não contemplados nesta pesquisa e/ou a replicação de tais parâmetros em outros cenários.

Dada a importância da aprendizagem informal no contexto de trabalho, espera-se que as contribuições deste estudo abram uma possibilidade de enfrentamento às barreiras para a aprendizagem, estimulando as organizações, em especial as públicas, a fugirem do modelo tradicional mecanicista de trabalho, apostando em processos dinâmicos e furtivos e ampliar e fortalecer mecanismos de desenvolvimento de pessoas.

\section{REFERÊNCIAS}

ABBAD, G.; BORGES-ANDRADE, J. E. Aprendizagem humana em organizações de trabalho. In.: ZANELLI, J.C.; BORGES-ANDRADE, J.E.; BASTOS, A.V.B. Psicologia, organizações e trabalho no Brasil. Porto Alegre: Artmed, p. 237-275, 2004.

ANTONACOPOULOU, E. Desenvolvendo gerentes aprendizes dentro de organizações de aprendizagem: o caso de três grandes bancos varejistas. In: EASTERBY-SMITH, M.; BURGOYNE, J.; ARAÚJO, L. (Org.) Aprendizagem organizacional e organização de aprendizagem: desenvolvimento na teoria e na prática. São Paulo: Atlas, p. 263292, 2001.

ANTONACOPOULOU, E. Individuals' responses to change: the relationship between learning and knowledge. Creativity and Innovation Management, v. 8, n. 2, p. 1-22, 2002.

BERG, S.; CHYUNG, S. Y. Factors that influence informal learning in the workplace. Journal of Workplace Learning, v. 20, n. 4, p. 229-244, 2008.

BRANDI, U.; ELKJAER, B. Organizational Learning Viewed from a Social Learning Perspective. In.: EASTERBY-SMITH, M.; LYLES, M. Handbook of Organizational Learning and Knowledge Management. Oxford: Wyley, p. 23-42, 2011.

CALDEIRA, A.; GODOY, A. S. Barreiras e incentivos à aprendizagem organizacional: um estudo de caso. Revista de Gestão, v. 18, n. 4, art. 9, p. 513-530, 2011

$\mathrm{CHOI}, \mathrm{W}$. Influences of formal learning, personal characteristics, and work environment characteristics on informal learning among middle managers in the Korean banking sector. Tese de Doutorado. The Ohio State University, Ohio, 203 f., 2009

COELHO JUNIOR, F. A.; BORGES-ANDRADE, J. E. Uso do conceito de aprendizagem em estudos relacionados ao trabalho e organizações. Paidéia, v. 18, n. 40, p. 221-234, 2008.

COELHO JUNIOR, F. A.; MOURÃO, L. Suporte à Aprendizagem Informal no Trabalho: uma Proposta de Articulação Conceitual. Revista de Administração Mackenzie, v. 12, n. 6, p. 224-253, 2011.

CONLON, T. J. A review of informal learning literature, theory and implications for practice in developing global professional competence. Journal of European Industrial Training, v. 28, n. 2/3/4, p. 283-295, 2004.

COSTA, L. A. Ambiente Organizacional e sua influência no processo de aprendizagem dos indivíduos. In.:

ANTONELLO, C. S.; GODOY, A. S. Aprendizagem Organizacional no Brasil. Porto Alegre: Bookman, p. 301-328, 2011.

CROSSAN, M.; LANE, H.; WHITE, R. An organizational learning framework: from intuition to institution. Academy of Management Review, v. 24, n. 3, p. 522-537, 1999.

EASTERBY-SMITH, M.; ARAUJO, L. Aprendizagem Organizacional: Oportunidades e Debates Atuais. In.: EASTERBYSMITH, M.; BURGOYNE, J.; ARAUJO, L. Aprendizagem organizacional e organização de aprendizagem:

Desenvolvimento na Teoria e na Prática. São Paulo: Atlas, p. 15-38, 2001.

ELKJAER, B. Em busca de uma teoria de aprendizagem social. In: EASTERBY-SMITH, M.; BURGOYNE, J.; ARAÚJO, L. Aprendizagem organizacional e organização de aprendizagem. Atlas: São Paulo, p. 100-118, 2001. 
ELKJAER, B. Organizational learning: the "third way". Management Learning, v. 35, n. 4, p. 419-434, 2004.

FLACH, L.; ANTONELLO, C. S. A Teoria sobre Aprendizagem Informal e suas implicações nas organizações. Revista eletrônica de Gestão Organizacional, v. 8, n. 2, p. 193-208, mai.lago., 2010.

GHERARDI, S. From organizational learning to practice-based knowing. Human Relations, v. 54, n. 1, p. 131-139, 2001.

GHERARDI, S.; NICOLINI, D.; ODELLA, F. Toward a social understanding of how people learn in organizations: the notion of situated curriculum. Management Learning, v. 29, n. 3, p. 273-297, 1998.

HILGARD, E. R. Teorias da Aprendizagem. São Paulo: EPU, 1973.

LAVE, J.; WENGER, E. Situated learning: legitimate peripheral participation. Cambridge: Cambridge University Press, 1991.

LA TAILLE, Y. Desenvolvimento do Juízo Moral e Afetividade na Teoria de Jean Piaget. In.: LA TAILLE, Y., OLIVEIRA, M. K., DANTAS, H. Piaget, Vygotsky, Wallon: Teorias Psicogenéticas em Discussão. São Paulo: Summus, 1992.

LIMA, J. O. Aprendizagem e desenvolvimento de competências coletivas na Secretaria de Recursos Humanos (SRH) da Universidade Federal de Campina Grande. Dissertação (Mestrado em Administração) - Universidade Federal da Paraíba, João Pessoa, 151 f., 2013.

LOHMAN, M. C. A survey of factors influencing the engagement of two professional groups in informal workplace learning activities. Human Resource Development Quarterly, v. 16, n. 4, p. 501-527, 2005.

MALHOTRA, N. Pesquisa de Marketing: uma orientação aplicada. Porto Alegre: Bookman, 2006.

MARSICK, V. J.; WATKINS, K. E. Informal and Incidental Learning. New Directions for Adult and Continuing Education, v. 89, p. 25-34, 2001.

MARSICK, V. J.; YATES, J. L. Informal Learning and Complex Problem Solving of Radiologic Technologists Transitioning to the Workplace. In: HOU, H. New Research on Knowledge Management Applications and Lesson Learned. Croatia: InTech. 2012. p.171-194.

NILSSON, S.; RUBENSON, K. On the determinants of employment-related organised education and informal learning Studies in Continuing Education, v. 36, n. 3, p. 304-321, 2014.

NOGUEIRA, R. A.; ODELIUS, C. C. Aprendizagem: Evolução no contexto das teorias organizacionais. Perspectivas em Gestão \& Conhecimento, v. 5, n. 1, p. 3-18, 2015.

NUNES, C. H. S. S.; HUTZ, C. S. Construção e validação de uma escala de extroversão no modelo dos Cinco Grandes Fatores de Personalidade. Psico-USF, v. 11, n. 2, p. 147-155, 2006.

NUNES, C. H. S. S. \& HUTZ, C. S. Escala Fatorial de Socialização - Manual técnico. São Paulo: Casa do Psicólogo, 2007.

PASSOS, M. F. D.; LAROS, J. A. Construção de uma escala reduzida de Cinco Grandes Fatores de personalidade. Avaliação Psicológica, v. 14, n. 1, p. 115-123, 2015.

REATTO, D.; GODOY, A. S. Aprendizagem Informal no Setor Público: Foco nas Interações Sociais e Contexto Organizacional Informal. Revista Pensamento Contemporâneo em Administração, v. 11, n. 1, p. 17-36, 2017.

ROBBINS, S. P. Comportamento Organizacional. São Paulo: Prentice-Hall, 2002.

SOUZA, D. L.; SOUSA, J.S.; FERRUGINI, L.; ZAMBALDE, A. L. Teorias da aprendizagem e gestão do conhecimento: um alinhamento teórico. Revista Pensamento Contemporâneo em Administração, v. 7, n. 4, p. 42-57, 2013.

TRIVIÑOS, A. N. S. Introdução à pesquisa em Ciências Sociais: a pesquisa qualitativa em Educação. São Paulo: Atlas, 2009.

TSANG, E. W. K. Organization learning and the learning organization; a dichotomy between descriptive and prescriptive research. Human Relations, v. 50, n. 1, p. 73-89, 1997.

WAHAB, M. S. A.; SAAD, R. A. J.; SELAMAT, M. H. A survey of work environment inhibitors to informal workplace learning activities amongst Malaysian accountants. Procedia - Social and Behavioral Sciences, Kuala Lumpur, Malaysia, v. 164, p. 409-414, 2014. 